\title{
Modeling, Control and Placement of FACTS Devices:
}

\section{A Review}

\author{
Ayesha Haroon $^{1 \mathrm{a}}$, Irfan Shafqat Javed ${ }^{1 \mathrm{~b}}$, Huma Rehman Baigic, Ali Nasir ${ }^{1 \mathrm{~d}}$, \\ Arslan Ashraf ${ }^{1 \mathrm{e}}$
}

RECEIVED ON 28.02.2019, ACCEPTED ON 26.07.2019

\begin{abstract}
Over the past two decades, developing distributed energy sources in electric power grid have created new challenges related to the power quality, voltage adjustment and proficient energy utilization. Power electronic converters are widely used to interface the emerging energy systems (without and with energy storage) and smart buildings with the transmission and distribution systems. Flexible Ac Transmission Systems (FACTS) and Voltage-Source Converters (VSC), with smart dynamic controllers, are emerging as stabilization and power filtering equipment to improve the power quality. FACTS devices are of vital significance for tackling the problem of voltage instability which is inevitable and leads to losses in transmission system networks. These devices provide fast voltage regulation, ensure system stability and reactive power compensation. In this regard, modeling, control and appropriate placement of these devices in the transmission lines have been of great importance for researchers of power transmission systems. By using high speed power electronic converters, FACTS perform many times faster than the conventional compensation techniques. FACTS not only provide fast voltage regulation but also damping of active power oscillations and reactive power compensation. Hence, they increase the availability and reliability of the power systems. But, the functioning of a FACTS device extremely reckons upon its parametric quantity, appropriate placement, and sizing in the power network. In this paper, an extensive literature survey is presented to discuss and investigate these parameters of FACTS devices.
\end{abstract}

Keywords: Flexible AC Transmission Systems, Modeling, Placement, Control.

\section{INTRODUCTION}

$\mathrm{T}$ The need of transmission systems arises from the fact that generation systems cannot be located near the load centres. The various factors governing this issue are pollution, smoke and noise, land constraints and the availability and transport of fuel. According to the Environmental Protection Agency (EPA) standards no power plant can emit more than $1400 \mathrm{lbs} / \mathrm{MW}$ of carbon dioxide. The power plants emitting this high concentration of $\mathrm{CO}_{2}$ cannot be installed near the localities. The most crucial constraint in the hydro power plant is the selection of a suitable site. It is more convenient to install the fuel based generating station near its source so as to limit the cost of the transport of fuel. All these constraints demand a proficient transmission network so that the electric power is transferred to load centres.

Over the years, major challenges have been faced by the power system engineers in the transmission of electric power. A transmission system must be efficient enough to deliver maximum power with minimum losses. The voltage levels chosen for the transmission must be such that they minimize the losses as well as cost. But, often, we have to make a

${ }^{1}$ Department of Electrical Engineering, University of Central Punjab, Lahore, Pakistan.

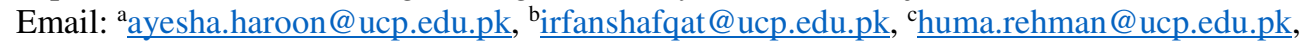

da.nasir@ucp.edu.pk (Corresponding Author), ${ }_{\text {earslan.ashraf@ucp.edu.pk }}$

This is an open access article published by Mehran University of Engineering and Technology, Jamshoro under CC BY 4.0 International License. 
trade-off between cost and transmission losses. Moreover, the design of a transmission system must be such that it may address external disturbances and noise. All these challenges must be confronted for a sophisticated transmission system.

Most of the world's electric power supply arrangements are widely integrated as there can be inter-utility, inter- regional or international interconnections. The persona of transmission system networks is to pool these interconnected power systems and load centres. Nevertheless, as the power system develops, it becomes progressively intricate; consequently, it can become less secure to line outages, contingencies and other faults. These disturbances produce oscillations in the power system. If the system has appropriate damping or inertia, these oscillations may damp out. However, inability of damping system for damping these oscillations, the phenomenon of voltage imbalance occurs. This can lead to inadvertent tripping of generators and can lead to cascaded failures resulting in a complete black out [2].

For safe operation of electric power flow, voltage of all the phases must be balanced. Voltage imbalance occurs due to shortfall of reactive power at load buses under accumulated loading conditions or during contingencies. This can be reinforced using FACTS controllers like Thyristor Controlled Series Compensator (TCSC), Static VAR Compensator (SVC) etc. [3]. FACTS devices are adequate to control the network constraint in a very quick mode by reactive power management and to ameliorate the transient stability of an arrangement. Thus, the major goal of given devices is to upgrade the controllability, load-ability and hence the usable transmission capacity of the power system.

\section{NEED OF FACTS CONTROLLERS}

The major problem that a power system has to face is voltage instability as a power system is mostly reactive [4]. The active power provided by the synchronous generator is dictated by the mechanical input power. Whereas, the reactive power depends upon the load requirements. Voltage break is the phenomenon due to which the voltage downfalls to a minimum, exceptionable point due as consequence of occurrence of events resulting in voltage imbalance. To overcome this problem, reactive power compensation is an essential criterion to sustain the voltage profile in the system.

At present, more innovative technology is utilized for authentic cognitive operation of transmission and distribution in power system which enables better utilization and control of existing transmission systems. FACTS devices are capable of providing voltage support by means of fast acting thyristor switching. These devices can increase power transfer ability of the line and corroborate the network to compatible with sufficient tolerances of stability. They can be employed in the transmission systems to compensate for the reactive power losses. They are capable of system compensation by means of series, shunt, series-series or series-shunt controllers.

\section{TYPES}

Over the past few years, FACTS devices are proven to be more efficacious in addressing the power quality issues. These issues involve voltage spikes, dips, surges and transients etc. They are widely used to ensure satisfactory voltage levels during over voltage and under voltage conditions. Basically seven types of FACTS devices have been discussed below with respect to their modelling, control and placement in transmission line.

\subsection{Thyristor Controlled Series Compensator}

\subsubsection{Modeling}

TCSC is a series device which permits a quick and continuous change in transmission network impedance. It consists of four components, a capacitor Bank-C, Bidirectional thyristor Switch, a bypass inductor L and a Metal Oxide Varistor (MOV) as represented in Fig. 1 [5].

The purpose of MOV is to protect the capacitor banks during transients. The firing angle $\alpha$ of the bidirectional switch is controlled in response to the system voltage profile. Variation of firing angles introduces a variable reactance of the compensator at Mehran University Research Journal of Engineering and Technology, Vol. 39, No. 4, October 2020 [p-ISSN: 0254-7821, e-ISSN: 2413-7219] 
the fundamental frequency. Mondal et.al. [6] have proposed the following relation between thyristor firing angle $(\alpha)$ and Steady State Reactance $\left(\mathrm{X}_{\mathrm{TCSX}}\right)$.

$\mathrm{X}_{\text {TCSC }}=-X_{C}+C_{1}\left(2((\pi-\alpha)+\sin (2(\pi-\alpha)))-C_{2} \cos ^{2}(\pi-\alpha) \omega \tan (\omega(\pi-\alpha))-\tan (\pi-\alpha)\right)$

where, $\mathrm{X}_{\mathrm{C}}$ is capacitive reactance and $\mathrm{X}_{\mathrm{L}}$ is inductive reactance in relation to equivalent inductive capacitive reactance $X_{\mathrm{LC}}$ in following equation

$\mathrm{X}_{\mathrm{LC}}=\frac{\mathrm{X}_{\mathrm{C}} \mathrm{X}_{\mathrm{L}}}{\left(\mathrm{X}_{\mathrm{C}}-\mathrm{X}_{\mathrm{L}}\right)}$

$\mathrm{C}_{1}=\frac{\mathrm{X}_{\mathrm{C}}+\mathrm{X}_{\mathrm{LC}}}{\pi}, \mathrm{C}_{2}=\frac{4 \mathrm{X}_{\mathrm{LC}}^{2}}{\pi \mathrm{X}_{\mathrm{L}}}$

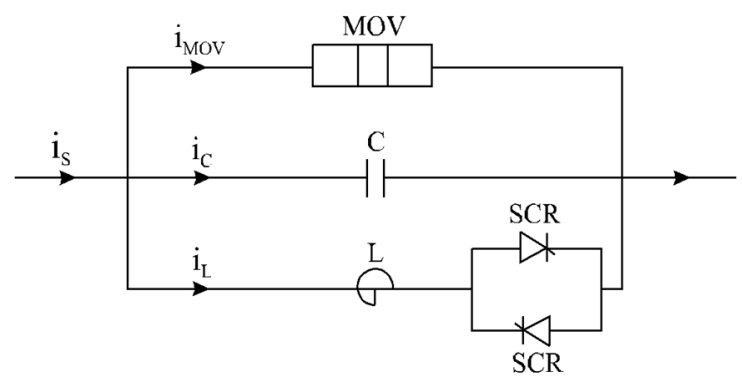

Fig. 1: Thyristor Controlled Series Compensator

\subsubsection{Control}

To improve the transient behaviour of this device, a Proportional Integral Derivative (PID) controller must be employed with model which is represented earlier in Fig. 1 and its control loop with detailed transfer function analysis is discussed in [1]. Another control technique of TCSC is presented in [7], which is manipulated through adjusting the stage deferral of the thyristor pulses to the Phased Lock Loop (PLL) which is used to synchronize these pulses with line current. PI controller has been used with series compensator for filtering, this device consists of basically three blocks namely: signal conditioning, gain factor and a compensator [8]. Several researchers presented the effect of voltage break down in power networks based on some outcomes like point of break down and some other designing schemes. A different technique was presented in [9] to design the output feedback damping controllers and its installation is determined by analyzing the modes of its controllability. The Simulated Annealing (SA) algorithm in [9] is employed to optimize the controllers and also for control objectives. It also proposed a complete discussion on various measurable input signals which are used to design TCSC controllers. Recently, another application of TCSC in transmission line was proposed in [10] which justify the stability of power system in a very low cost.

\subsubsection{Placement}

Researchers have used various algorithms to examine the optimal placement and size of TCSC to attain maximum benefit from this device. These two constraints have been of great importance for researchers. Particle Swarm Optimization (PSO) technique combined with real time accelerating coefficients has been discussed in [11] for optimal placement of TCSC. The Line Stability Index (LSI) is utilized for proper sizing as well as to allow for precise indicant about the voltage imbalance in the system [12]. The value of LSI is zero at no load and 1 at voltage break down. Optimal location and size can be found out by reducing the LSI points of several lines. It is between two lines, it has to be minimized and is given by the expression:

$\operatorname{LSI}_{\mathrm{ij}}=\frac{4 \mathrm{X}_{\mathrm{ij}} \mathrm{QI}_{\mathrm{ij}}}{\left(\mathrm{V}_{\mathrm{i}} \sin \left(\mathrm{e}-\delta_{\mathrm{ij}}\right)\right)^{2}}$

Mondal et. al. [6] optimizes the gain, location, lead and lag time constant of TCSC by using classical PSO algorithm. This algorithm minimizes the Critical Damping Index (CDI). The CDI to be minimized is given by the equation:

$\mathrm{CDI}=\mathrm{J}=\left(1-\left|\zeta_{\mathrm{i}}\right|\right)$

A combined algorithm named Genetic Algorithm (GA) and PSO is utilized for the optimal placement of TCSC to reduce real power losses [11]. As given by Rashed et. al. [13], PSO converges faster than the GA. A global Harmony Search Algorithm (HAS) is discussed in [14] for the placement of TCSC as well as for system security. HAS also converges faster than the genetic algorithm. It minimizes a fitness function to obtain optimal location in terms of minimum cost and losses. The proposed fitness function having transmission coefficients including losses is as follows. 
Fitness $=\mathrm{a}_{1} . \mathrm{JP}+\mathrm{a}_{2} . \mathrm{JV}+\mathrm{a}_{3}$. (Total Investment Cost $)$ $+\mathrm{a}_{4}$. (Losses)

A placement technique was presented in [15] to lessen the transmission losses for proper voltage profile and also to increase the available capacity. Another technique was proposed named (Trajectory Sensitivity Analysis) TSA for transient stability at different considerations of a power system. A new method using Artificial Neural Network (ANN) was utilized for different load conditions to satisfy the voltage stability [16]. This network is applicable on IEEE-14 bus and IEEE-30 bus power system for the calculation of LSI. The Differential Evolution (DE) is also used by many researchers to select the ideal position and parameter estimation for the reduction of power loss in electric power networks.

\subsubsection{Applications}

TCSC can amend the transient stability of the system. It provides voltage support to the system. It can boost the dynamic performance of the system such as increasing power transfer capability. It can also be applicable for damping system oscillations and mitigating sub synchronous resonance.

\subsection{Static Synchronous Series Compensator}

The Static Synchronous Series Compensator (SSSC) is a series controller and has the ability of allowing reactive power compensation. Here, voltage acts as an output, having phase difference of $90^{\circ}$ with its line current, to manage both inductive and capacitive reactance [17]. SSSC can increase electric power flow ability of transmission line by minimizing its impedance.

\subsubsection{Modeling}

SSSC is the combination of VSC and a capacitor bank which is connected with an injection transfer. When utilized for reactive power remuneration just, the dc capacitors must give the dynamic power expected to balance for misfortunes in the framework. Something else, when real power infusion is embarked, the DC capacitor is likewise utilized as a storage device [18]. A current source converter based SSSC has been suggested in [17]. The primary side of every transformer is associated in series with the transmission line. The control goals of the SSSC are to keep the present steady and to give the network reactive power minimization as needed.

\subsubsection{Control}

Many researchers employed PLL and rotating frame transformer for the control of SSSC e.g. Ye et. al. [17] propose the controller of the form $u=-K x+T y_{r e f} M_{e}$ which results in transfer function after choosing appropriate $\mathrm{K}, \mathrm{T}$ and $\mathrm{M}$ matrices. Where $u$ is a control input having gain $K$ with multiple state variables. The dynamic performance of SSSC has been analyzed through a PID controller [19]. The control gains of PID are tuned using Artificial Bee Colony (ABC) optimization technique. The proposed configuration is given in Fig. 2.

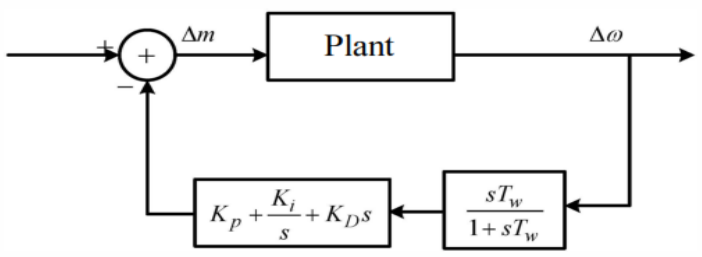

Fig. 2: PID Controller for SSSC

These controllers have been generally established in the feedback loop. Another filter is connected in cascade with PID controller to rule out any undesirable disturbance in the steady state. The controller relation along with the washout in the feedback path is given in [19]. Washout filter is used as high pass filter to improve the transient behaviour of plant as well as to fasten its response.

$H(s)=\left[K_{p}+\frac{K_{I}}{s}+K_{D} s\right]\left[\frac{s_{w}}{1+\mathrm{sT}_{w}}\right]$

Another model is used in [20] which used multiple gate pulses for thyristor switching to compensate reactive power flow as well as to stabilize the terminal voltage. Transient stability and small signal analysis of a power system was proposed in [21] to improve the performance of system. Panda et. al. [22] proposed a controller for specific design problem using the Real Coded Genetic Algorithm (RCGA) with time delay between two signals. A robust controller design in [23] was implemented to reduce the disturbances as well as system uncertainties. 


\subsubsection{Placement}

Due to continuous increase in electrical load, transmission lines get overloaded, which can further trip the electric power flow. Considering this problem, it is imperative to carefully devise the placement of controller in transmission lines. Hajforoosh et. al. [24] propose PSO technique for placement and sizing of SSSC and it minimizes a social welfare equation to alleviate congestion and maximize social benefit. Consequently, the goal of commercialize operator is to maximize the social welfare, including load flow equality and functional inequality restraints. Proposed objective function in [25] is as:

$$
\begin{aligned}
\max \left\{\sum_{j=1}^{\mathrm{N}}\left(\mathrm{a}_{\mathrm{ij}}+\mathrm{b}_{\mathrm{ij}} \mathrm{P}_{\mathrm{ij}}+\mathrm{c}_{\mathrm{ij}} \mathrm{P}_{\mathrm{ij}}^{2}\right)+\mid \mathrm{e}_{\mathrm{ij}} \sin \left(\mathrm { f } _ { \mathrm { ss } } \left(\mathrm{P}_{\mathrm{ij}}-\right.\right.\right. \\
\left.\left.\left.\mathrm{P}_{\mathrm{ji}}\right)\right) \mid \sum_{\mathrm{n}=-1}^{\mathrm{N}} \mathrm{Cx}_{\mathrm{c}, \mathrm{u}, \mathrm{k}} \frac{\mathrm{s}_{\mathrm{n}}}{\mathrm{s}_{\mathrm{n}}}\right\}
\end{aligned}
$$

GA is a widespread optimization purpose algorithm, founded on the mechanism of natural selection and genetic science. The proposed social welfare maximization equation is expressed as:

$\min _{\mathrm{P}_{\mathrm{w}}}\left\{\sum_{\mathrm{i}=1}^{\mathrm{N}_{\mathrm{D}}} \mathrm{B}_{\mathrm{Dj}}\left(\mathrm{P}_{\mathrm{D}}\right)+\operatorname{Cost}(\mathrm{FACTS})\right\}$

A predisposition based method for operational determination of SSSC placement in electricity market is discussed in [26]. It has employed less sensitivity and active power flow performance indices to determine the location for SSSC. The proposed indices are written as:

$\mathrm{PI}=\sum_{\mathrm{m}=1}^{\mathrm{N}_{\mathrm{L}}} \frac{\mathrm{W}_{\mathrm{m}}}{2 \mathrm{n}}\left(\frac{\mathrm{P}_{\mathrm{Lm}}}{\mathrm{P}_{\mathrm{L}}^{\max }}\right)^{2 \mathrm{n}}$

$\mathrm{a}_{\mathrm{k}}=\frac{\partial \mathrm{P}_{\text {loss }}}{\partial \Theta_{\mathrm{ij}}}$

Right hand side of the above expression (8) is equal to $\mathrm{k}$ less than the loss sensitivity with respect to SSC placed in line where $(\mathrm{k}=1, \ldots \mathrm{N})$

The objective function $\mathrm{f}$ is used as the reduction of total loss for voltage profile improvement.

$\min \mathrm{f}=\min \left(\mathrm{T}_{\text {loss }}\right)$
This objective function is minimized using improved particle swarm optimization technique for distributed SSC.

A new objective function is given in [27] to find out the optimal location of fact devices. It also proposed an installation technique of SSC by using iterative method implemented on 4-bus and 5-bus power system. Similarly, a method was proposed in [28] to find out the accurate placement of SSC controller that maximizes the available transfer capability of power system.

\subsection{Static VAR Compensator}

SVC is a shunt device which is capable of regulating the voltage to a set point during steady state and contingency preconditions. It can provide dynamic and fast acting reactive power after contingencies. SVC can also enhance power transfer capability, prevent over-voltages, minimize reactive power losses and mitigate power system oscillation.

\subsubsection{Modeling}

An SVC typically consists of a combination of two of the given devices

- TCR

- TSC

- $\mathrm{FC}$

- MSC or MSR

A typical model of SVC is shown in Fig. 3 [6].
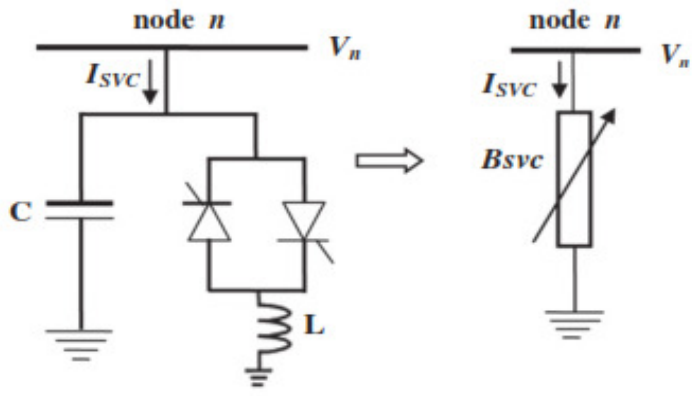

Fig. 3: Typical Model of SVC

The effective reactance $X_{e}$ offered by the SVC in [29] is given as: 
$X_{e}=X_{c}\left(\frac{\pi / r_{x}}{\sin 2 \alpha-2 \alpha+\pi\left(2-\frac{1}{r_{x}}\right)}\right)$

\subsubsection{Control}

Several control algorithms are projected in the literature to control switching of thyristor banks in SVC. Mishra discusses the application of rough fuzzy controller design for SVC to provide better control efficiency [30]. A fuzzy logic switching scheme with variable gain has been presented in detail. The magnitude of switching control signal depends on severity of disturbance. The signal diminished when disturbance ends to avoid unnecessary control action. A different optimization technique known as Bacterial Foraging Algorithm (BFA) to model a damping controller for SVC [31]. This research employed an objective function(J) which is totally dependent on time that includes speed deviations $\left(\Delta \mathrm{W}_{12}, \Delta \mathrm{W}_{23}, \Delta \mathrm{W}_{13}\right)$ as mentioned in the following equation:

$J=\int_{0}^{\infty} \mathrm{t}\left(\left[\Delta \mathrm{W}_{12}\right]+\left[\Delta \mathrm{W}_{23}\right]+\left[\Delta \mathrm{W}_{13}\right]\right) d \mathrm{t}$

SVC can also be used to mitigate sub synchronous resonance SSR in power systems. Therefore, an optimal control must be used for the damping of SSR. The results presented in [31] also shows that the optimal control performs better than the PID controller used for the same application. An additional SVC as well as STATCOM controller has been proposed in [32] which used $\mathrm{H}_{\infty}$ controller techniques to eliminate oscillations. An artificial neural network based technique is used to design an effective damping controller for SVC. The control loop of SVC controller is given in Fig.4.

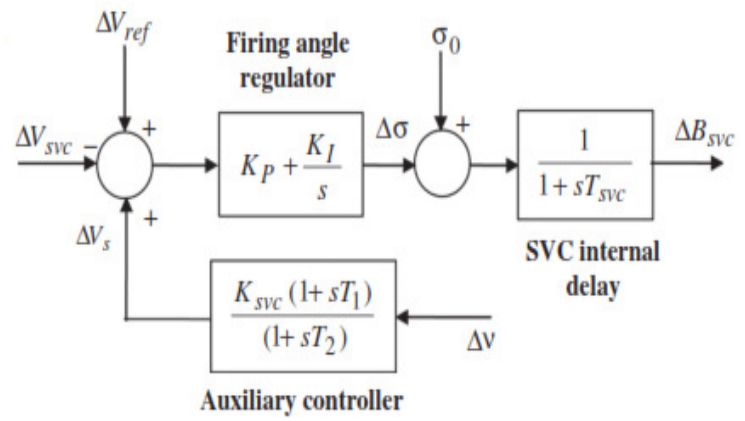

Fig. 4: Block Diagram for SVC Controller
An analytical approach was proposed in [33] for multiple SVC controllers to analyse the nonlinear interactions in power systems It also discusses the effects of SVC controllers on the stability of system named single machine dynamic load. For stability purposes, Chaotic PSO (CPSO) algorithm is used in which damping controllers were tested for proper system analysis [34]. A robust controller is recently proposed by using whale optimization technique for the transient stability of power system in [35].

\subsubsection{Placement}

The implementation of the Improved Harmony Search Algorithm (HIS) technique as a different optimization technique for governing the best positioning and sizing of SVC devices in a transmission line as introduced in [36]. A multi-objective function is considered to determine the optimal location and size of SVC. The objectives include the minimization of voltage deviation, active power loss and installation cost $\mathrm{C}_{\mathrm{SVC}}$ which are given as following expression:

$$
\mathrm{C}_{\mathrm{SVS}}=\sum_{\mathrm{k}=1}^{\mathrm{n}} 0.0003 \mathrm{Q}_{\mathrm{k}}^{2}-0.3051 \mathrm{Q}_{\mathrm{k}}+127.38
$$

The Optimal Power Flow (OPF) and the Low Discrepancy Sequence (LDS) based optimization techniques are employed to determine the optimal allocation of SVC. The OF (objective function) in [37] that minimizes the cost of generation $\left(\mathrm{C}_{\mathrm{r} 1}\right.$ and $\left.\mathrm{C}_{\mathrm{Qi}}\right)$ as well as the cost of devices $\left(\mathrm{C}_{\mathrm{SVC}_{\mathrm{i}}}\right)$ is expressed as:

$\mathrm{OF}=\min \left[\left(\sum_{\mathrm{i}=1}^{\mathrm{n}} \mathrm{C}_{\mathrm{r} 1}+\mathrm{C}_{\mathrm{Qi}}\right)+\sum_{\mathrm{j}=1}^{\mathrm{m}} \mathrm{C}_{\mathrm{SVCi}}-\mathrm{C}_{\mathrm{with}}\right]$

An appropriate approach was published in [37] to calculate the network security indices for optimal placement of SVC controllers. Singh suggested a method called Reactive Power Spot Price Index (QSPI) under various loading conditions to verify the performance and placement of controller [38].

\subsection{STATCOM}

The Static Synchronous Compensator (STATCOM) are such compensators which do not require large capacitive and inductive circuits as in SVC. STATCOM is able to provide greater reactive current generation at depressed system voltages. It can provide voltage support and enhance the damping of 
inter-area oscillations [39]. It successfully improves the system steady state and dynamic exhibitions, controls power factor, minimize losses and permits power flow in existing lines, thus results in the post fault recovery of a transmission network.

\subsubsection{Modeling}

A simplified circuital model for STATCOM is presented in Fig. 5.

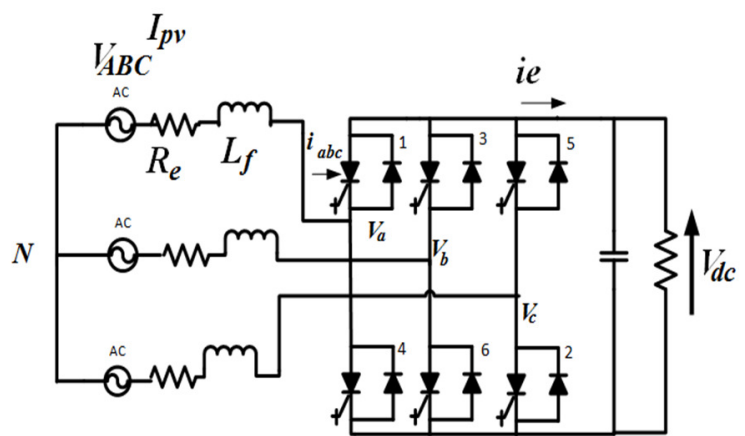

Fig 5: Simplified Circuital Model for STATCOM

A basic structure of a 6 pulse STATCOM connected to a power grid through a filter and transformer is presented in Fig. 5. Multilevel converter topologies have become an important technology in FACTS. Multilevel converters are made of multiple, identical $\mathrm{H}$ bridge inverters. A multilevel converter based STATCOM as presented in [40] consists of three major parts. A VSC with separate DC capacitors, coupling reactors and controllers.

\subsubsection{Control}

The feedback control strategy is analyzed and configured in [40] to execute reactive power compensations as well as capacitor voltage balancing in a multilevel converter. A nonlinear control of STATCOM based on differential algebra theory is presented to perform better than the conventional linear control. Therefore, a rule based controller for STATCOM is used to improve system damping for all load conditions. Kavitha and Neela [41] present a coordinated design of STATCOM which determines the controller design parameters using PSO optimization. An Equivalent Current Injection (ECI) model of STATCOM has been presented in Fig.6.
STATCOM controllers were discussed to ensure the power quality and its effectiveness and proper modelling of this controller has been discussed in [42]

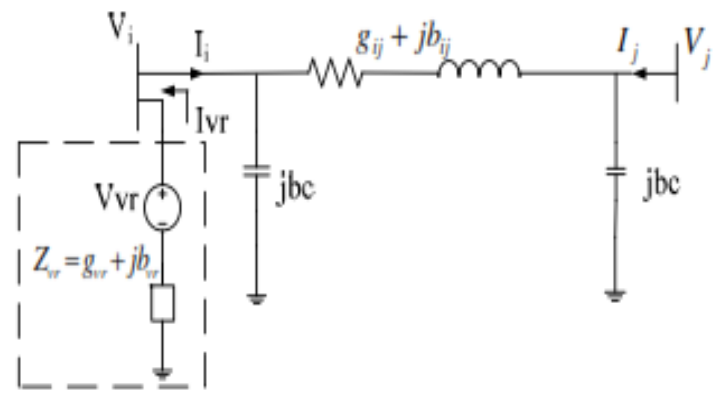

Fig. 6: STATCOM as in Equivalent Circuit Injection (ECI) Model

which used the Genetic and Evolutionary Algorithm (GEA) to ameliorate the performance of system. The applications of STATCOM controllers were presented in [43] with their simulation results using PSCAD/EMTPDC.

\subsubsection{Placement}

To attain maximum benefit from the device, it should be positioned at some optimum placement in the power system. Literature has proposed several optimization methods for the allocation and sizing of STATCOM. PSO is a creative technique motivated by the behaviour of birds and fish. The criteria used in PSO is that the voltage digressions at each bus does not outperform a certain boundary. The objective function $(J)$ used in [44] is a weighted sum of voltage variations $\left(V_{i}\right)$ and size of STATCOM, as expressed in following equation:

$\min (J)=\left(\sum_{i=1}^{45}\left(V_{i}-1\right)^{2}\right)^{0.5}+\frac{\eta}{500}$

It also determined the optimal placement of STATCOM in a two area system using the objective function for transient stability. A hybrid algorithm, consisting of ant-colony optimization and genetic algorithm, optimizes the location and size of ECI based STATCOM. A combined voltage loss sensitivity index has been defined in [45] as following set of equations:

$\operatorname{VLSI}(j)=\alpha \operatorname{VLIn}(j)+\beta \operatorname{LSIn}(j), \quad j=1,2, \ldots, N$ 
where, $\mathrm{n}$ represents normalized values, $\mathrm{N}$ is the number of buses, VSI is voltage sensitivity index, LSI is loss sensitivity index, and $\alpha, \beta$ are weight factors.

To determine the optimal location of STATCOM, the optimal size is managed using genetic algorithm. It presents a graphical user interface which is able to find the optimal location and size of multi-type FACTS device. STATCOM has also been efficiently employed in Distributed Generation (DG) systems. A systematic methodology using STATCOM for fast voltage recovery at the DG bus is presented in [46]. A stability evaluation of DG systems with index based placement of STATCOM has been investigated in [46]. Its objective function minimizes system energy loss and capacitor investment cost and is expressed as:

$\min _{\mathrm{q}^{0}, \mathrm{q}^{\mathrm{j}}} \sum_{\mathrm{i}=1}^{\mathrm{l}} \mathrm{C}_{\mathrm{i}}\left(\mathrm{q}_{\mathrm{i}}^{0}\right)+\sum_{\mathrm{j}=1}^{\mathrm{L}} \mathrm{k}_{\mathrm{e}, \mathrm{j}} \mathrm{T}_{\mathrm{j}} \mathrm{P}_{\text {loss }, \mathrm{j}}\left(\mathrm{x}^{\mathrm{j}}, \mathrm{q}^{\mathrm{j}}\right)$

The results in [46] depict that STATCOM controller having multiple variations in its voltage ratio does not prove actual placement under these variations but it only provides excellent damping functionalities as compared to lying at some different nodes. Proper optimal location and sizing of STATCOM controllers were investigated by using PSO and also for voltage profile performance. Sensitivity analysis is used to preserve energy margins for finding the optimal location of STATCOM controllers.

\subsection{Interline Power Flow Controller}

The Interline Power Flow Controller (IPFC) can achieve a general active and reactive power flow and its compensation in transmission network. This ability makes it feasible to balance both active and reactive power flow between the transmission lines, and to increase the viability of the counterbalancing framework against dynamic disturbances.

\subsubsection{Modeling}

An IPFC encloses a series voltage into a transmission line by utilizing a voltage source converter. An IPFC can compensate two or more lines simultaneously. To build the structure preserving energy function of an IPFC, an IPFC has to be comprised by an injection model [47]. The injection model of an IPFC with two series branches is shown in Fig.7.
A two converter IPFC using two series injected voltage sources are used to control power quality and its flow. For a given magnitude of series injected voltage, the relation between active power and angle of injected voltage is given by the author in [47].

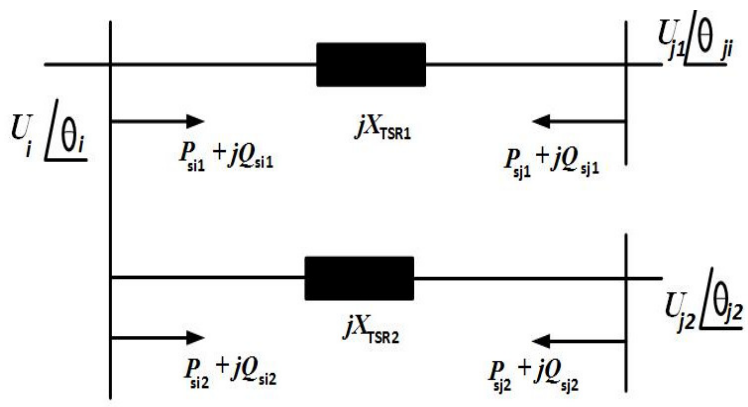

Fig. 7: The Injection Model of an IPFC with Two Series Branches

\subsubsection{Control}

The suggested control technique of an IPFC is based on energy function is discussed in [48]. The principle is based on the numerical search for the minimum of time derivative of the energy function given by:

$\mathrm{V}(\omega, \phi, \mathrm{U})=\mathrm{V}_{\mathrm{k}}(\omega)+\mathrm{V}_{\mathrm{p} 1}(\phi, \mathrm{U})+\mathrm{V}_{\mathrm{p} 2}(\phi)+\mathrm{K}$

where $\phi=\left[\begin{array}{ll}\delta^{\mathrm{T}} & \Theta^{\mathrm{T}}\end{array}\right], \delta$ is rotor angles; $\theta$ is busvoltage angles; $\omega$ is rotor velocities; and $U$ is busvoltage magnitudes.

A basic control technique has been proposed for IPFC to realize the power flow control and A general control scheme and a special control for IPFC control scheme has been presented in [49] as shown in Fig.8.

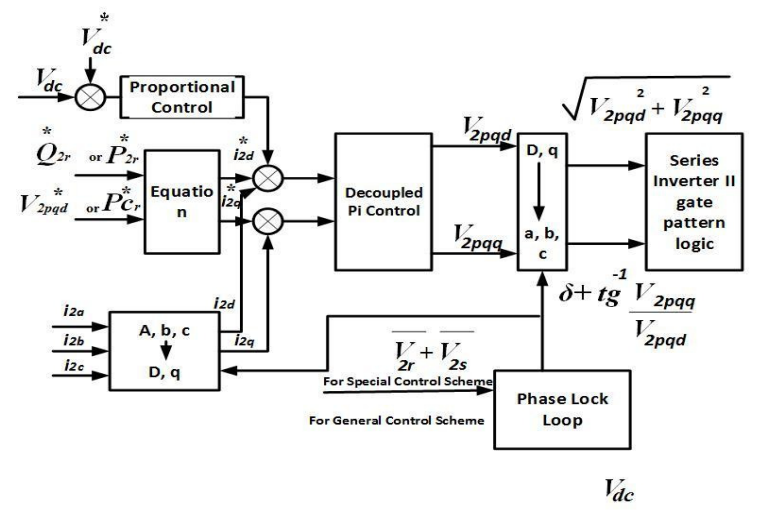

Fig. 8: General and Special Control Scheme for IPFC Control 
Many researchers also presented damping based IPFC controllers to analyse the torque contribution in the power system. A unique design of generalized controller is presented in [50] for power flow using IPFC.

\subsubsection{Placement}

To ameliorate the voltage profile of the system, IPFC has to be arranged at an efficacious positioning in the power system. A hybrid technique cascaded with GA and GSA is represented in [51]. Proper placement of IPFC controller is used to stabilize the voltage of power network. The optimal location of the controller is found using GA. The proper parameters to ameliorate the voltage profile of the system are found using GSA. Another algorithm uses a combination of Integrated technique and ANN in the nominated algorithm to find out the proper placement localizations for IPFC [52].

The sizing of IPFC in the network is articulated as an optimization problem in [53] to lessen the transmission line losses. The minimization of total $\operatorname{cost} \mathrm{T}_{\text {cost }}$ (active power generation and cost of installation) is taken as the objective function in [53], as expressed:

$\min \left(\mathrm{T}_{\text {Cost }}\right)=\mathrm{C}_{1}\left(\mathrm{P}_{\mathrm{G}}\right)+\mathrm{C}_{2}(\mathrm{IP})$

The optimal location is determined by using the Lagrangian Relaxation (LR) and ABC algorithm.

\subsection{Unified Power Flow Compensator}

The Unified Power Flow Compensator (UPFC) is a versatile device which is used to control the active and reactive power flow through the line independently. It is multi-functional power flow controller having multiple abilities like to maintain terminal voltage at desired values, line compensation and phase angle detection as well as regulators [54]. UPFC is the combination of STATCOM and SSSC. The idea of UPFC makes it conceivable to deal with all the power stream control and transmission line compensation issues. UPFC injects a voltage of variable magnitude in series with the transmission line whose phase angle can vary from 0 to $2 \pi$ with respect to terminal voltage.
The main parts of the UPFC are two three phase converters, two coupling transformers connecting the converters to the transmission lines and a dc link capacitor, as shown in Fig.9.

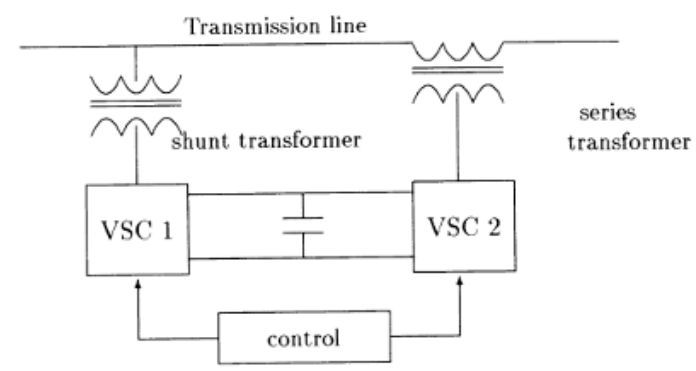

Fig. 9: Simplified Configuration of UPFC

\subsubsection{Modeling}

A UPFC can be represented by two voltage sources. These sources represent the output voltage of the two converters and the impedances are the impedance of coupling transformers [55]. Equation 18 represents the power frequency model of a UPFC for dynamic study

$\mathrm{CV}_{\mathrm{d}} \frac{\mathrm{dV} \mathrm{d}}{\mathrm{dt}}=\left(\mathrm{P}_{1}-\mathrm{P}_{2}\right) \mathrm{S}_{\mathrm{B}}$

The presented frequency model works very well with the dynamic power system with accuracy. Normally the UPFC model consists of two voltage source converters, two magnetic circuits, two coupling transformers, four mechanical switches, two electrical switches, current and voltage sensors and a controller.

\subsubsection{Control}

The control of UPFC can be bifurcated into two parts. The STATCOM is controlled in such a way that it ingests or engenders the compulsory VARS at the point of connection. SSSC injects a series voltage into the transmission line. The control of STATCOM and SSSC is represented in Fig.10.

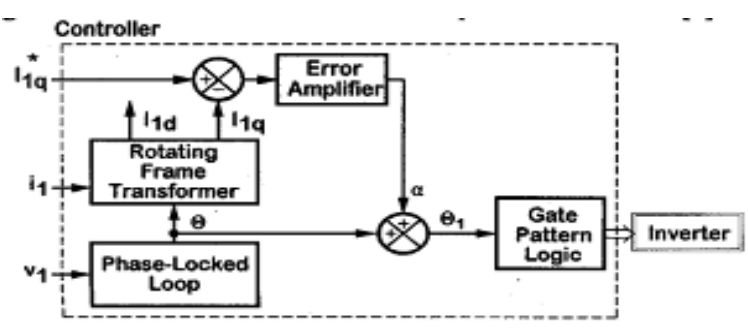

Fig. 10: Control of STATCOM and SSSC 
The control scheme discussed in [56] also includes both series and shunt control. The voltage injected in series with the transmission line can be divided into direct and quadrature components. An add-on selftunning controller for UPFC is discussed in [57]. If only PI controller were used, it would not be able to adapt to change system conditions. The self-tunning control copes to system alteration and offers excellent tracking ability.

\subsubsection{Placement}

UPFC is a tool used to assure the voltage levels at the sending end and the active and reactive power flows at the receiving end bus. However, to achieve full functionality of UPFC, it is mandatory to install it at an effective location in the power system. Laifa and Boudour [58] consider the security of electric power network as well as, it discusses the results after applying optimization criteria. A modification of PSO namely Perturbed PSO has been applied to find the optimal location and parameter settings of UPFC.

The immune algorithm presented in [59] is used to find the optimal location $\mathrm{L}(\mathrm{x})$ and parameters of UPFC. The objective function is to minimize the cost of active and reactive power generation and installation cost of $\mathrm{UPFC}(\mathrm{J})$ which is given as:

$\min (\mathrm{L}(\mathrm{x}))=\mathrm{f}(\mathrm{X})+\mathrm{PF} \cdot|\mathrm{J}-1|$

$\mathrm{J}=\prod_{\text {line }} \mathrm{OVL}_{\text {line }} \times \prod_{\text {Bus }} \mathrm{VS}_{\mathrm{BUS}}$

It has been observed that increase in load can cause instability in power system and optimal positioning of UPFC can reinstate the system to balanced condition. Genetic algorithm is generally applied as an optimal placement method for UPFC. A novel method known as cat swarm optimization technique is proposed in [60] to discern the optimal placement and sizing of multiple UPFCs under large contingencies. The objective function consists of three parts. First part is concerned with the voltage levels. Second part consists of optimal location and size of UPFC. And the third part is maximum load-ability of power networks. The expression for objective function (F) as a function of multi objective functions with cost coefficients are expressed as:
$\mathrm{F}=\varphi_{1} \mathrm{~F}_{1}+\varphi_{2} \mathrm{~F}_{2}+\varphi_{3} \mathrm{~F}_{3}$

Aghazadeh et.al. [61] address a new fuzzy based optimization technique namely multi objective honey bee mating optimization. Maximization of total revenue and minimization of voltage divergence are considered for the objective functions.

\subsection{Distributed Power Flow Controller}

The Distributed Power Flow Controller (DPFC) utilizes the Distributed FACTS (D-FACTS) concept and is derived from the UPFC. The DPFC can be regarded as a UPFC with an eradicated common dc link. It engages multiple small-size single-phase converters instead of one three-phase series converter in the UPFC [62]. Appropriate sizing, tuning and placement is an important part of FACTS installation. For this purpose, an optimization procedure must be employed. This problem optimizes various objective functions such as voltage profile, voltage stability, loss of power and operational cost. Shrivastav et. al. [63] proposed the design of proper location and size of the device. The control capability of both DPFC and UPFC are same. A case study is proposed in [64] based on infinite bus bar system to improve the quality of power by using DPFC. The design problem of a FACTS device is formulated as an objective function which can be used for the improvement of transient stability, voltage profile, losses minimization as well as minimization of cost [65]. This objective function can be minimized by using an optimization technique. Some of the algorithms that are widely discussed as SFLA (Shuffled Frog Leaping Algorithm), PSO and GA can be used for the placement of FACT device. But proper placement of DPFC has not been analyzed so far.

A detailed comparative analysis of each device with respect to its control and placement has been discussed in Table 1. It clearly shows that every technique differs from others in each domain.

\section{CONCLUSION}

FACT devices are of great importance for stability, voltage regulation, damping the system oscillation and reactive power compensation of power networks. 
FACTS devices are more efficient and fast as compared to traditional compensation techniques. In regard to this, the placement and sizing of these devices is an assiduous task. So far, various researchers have proposed the modeling, control and optimal sizing of several FACT devices.

In this paper multiple FACT devices has been discussed in regard to their modeling, control and optimal placement in power systems. It has been investigated that the modeling of DPFC has been proposed by various authors, but the control and optimal placement of DPFC is still unexplored. In this regard, the control and placement of DPFC in power systems can be suggested as a future work.

\section{ACKNOWLEDGEMENT}

Authors are very grateful to the management of the University of Central Punjab, Lahore, Pakistan, for providing us platform to carry out this research.

\section{REFERENCES}

[1] Yang, C. F., Lai, G. G., Lee, C. H., Su, C. T., Chang, G. W., "Optimal Setting of Reactive Compensation Devices with an Improved Voltage
Stability Index for Voltage Stability Enhancement", International Journal of Electrical Power and Energy Systems, Vol. 37, No.1, pp 50-57, 2012.

[2] Rahimzadeh, S., Bina, M. T., "Looking for Optimal Number and Placement of FACTS Devices to Manage the Transmission Congestion", Energy Conversion and Management, Vol. 52, No.1, pp 437-446, 2011.

[3] Srivastava, L., Dixit, S., Agnihotri, G., "Optimal Location and Size of TCSC for Voltage Stability Enhancement Using PSO-TVAC", Proceedings of the IEEE Conference on Power and Energy Systems: Towards Sustainable Energy, pp. 1-6, 2014.

[4] Kundur, P., Paserba, J., Ajjarapu, V., Andersson, G., Bose, A., Canizares, C., Cutsem, T. V., "Definition and Classification of Power System Stability", IEEE Transactions on Power Systems, Vol. 19, No.2, pp 1387-1401, 2004.

[5] Li, B. H., Wu, Q. H., Turner, D. R., Wang, P. Y., Zhou, X. X., "Modelling of TCSC Dynamics for Control and Analysis of Power System Stability", International Journal of Electrical Power and Energy Systems, Vol. 22, No.1, pp. 43-49, 2000.

\begin{tabular}{|c|c|c|c|c|}
\hline No & Device & Control & Placement & \\
\hline No. & Name & Techniques & Techniques & Findings \\
\hline . & TCSC & SA & $\begin{array}{l}\text { PSO, LSI, GA, } \\
\text { Global HAS, ANN, } \\
\text { DE }\end{array}$ & $\begin{array}{l}\text { For placement of TCSC, PSO and Global HAS converges } \\
\text { faster than LSI and GA. }\end{array}$ \\
\hline 2. & SSSC & $\begin{array}{l}\text { ABC, RCGA, } \\
\text { PID controller }\end{array}$ & PSO, GA, & $\begin{array}{l}\text { PSO is used for proper sizing } \\
\text { of SSSC and GA is used for } \\
\text { optimal placement. To tune the gains of PID controller, } \\
\text { ABC technique is used }\end{array}$ \\
\hline 3. & SVC & $\begin{array}{l}\text { Fuzzy Logic, } \\
\text { PID } \\
\text { controller, } \mathrm{H}_{\infty} \\
\text { controller, CPSO }\end{array}$ & HIS, QSPI & $\begin{array}{l}\text { HIS is far beetr than QSPI for placement of SVC. } \\
\text { To control SVC, fuzzy logic is used under external } \\
\text { disturbances as well. To eliminate oscillations, } \mathrm{H}_{\infty} \text { is used. } \\
\text { CPSO as damping controllers. }\end{array}$ \\
\hline 4. & $\begin{array}{l}\text { STAT } \\
\text { COM }\end{array}$ & PSO, GEA & PSO, Ant Colony,GA & $\begin{array}{l}\text { Combination of ant colony and GA place STATCOM better } \\
\text { than PSO alone. } \\
\text { PSO finds controller parameters and GEA is used to model } \\
\text { the controller. }\end{array}$ \\
\hline 5. & IPFC & $\begin{array}{c}\text { PI controller with } \\
\text { dq } \\
\text { modelling }\end{array}$ & GA, GSA,ANN & $\begin{array}{l}\text { Optimal location is found by GA and GSA is used to } \\
\text { improve voltage profile. } \\
\text { ANN used with other integrated technique to place IPFC }\end{array}$ \\
\hline 6. & UPFC & $\begin{array}{l}\text { Add-on self- } \\
\text { tuning controller, } \\
\text { PI controller }\end{array}$ & $\begin{array}{l}\text { Perturb PSO, GA, } \\
\text { immune algorithm, } \\
\text { cat swarm } \\
\text { optimization }\end{array}$ & $\begin{array}{l}\text { Immune algorithm minimizes the cost functions whereas } \\
\text { PSO and GA finds best placement of UPFC. } \\
\text { Self-tuning control offers excellent tracking. }\end{array}$ \\
\hline 7. & DPFC & & SFLA, PSO, GA & $\begin{array}{lcccc}\begin{array}{l}\text { Proper control and } \\
\text { has not been analyzed so far }\end{array} & & \text { of } & \text { DPFC } \\
\end{array}$ \\
\hline
\end{tabular}


[6] Mondal, D., Chakrabarti, A., Sengupta, A., "Optimal Placement and Parameter Setting of SVC and TCSC using PSO to Mitigate Small Signal Stability Problem", International Journal of Electrical Power and Energy Systems, Vol. 42, No.1, pp. 334-340, 2012.

[7] Jovcic, D., and Pillai, G. N., "Analytical Modeling of TCSC Dynamics", IEEE Transactions on Power Delivery, Vol. 20, No.2, pp 1097-1104, 2005.

[8] Chen, X. R., Pahalawaththa, N. C., Annakkage, U. D., Kumble, C. S., "Output Feedback TCSC Controllers to Improve Damping of Meshed Multi-Machine Power Systems", IEE Proceedings on Generation, Transmission and Distribution, Vol. 144, No.3, pp. 243-248, 1997.

[9] Chen, X. R., Pahalawaththa, N. C., Annakkage, U. D., and Kumble, C. S., "Design of Decentralised Output feedback TCSC Damping Controllers by using Simulated Annealing", IEE Proceedings on Generation, Transmission and Distribution, Vol. 145, No.5, pp. 553-558, 1998.

[10] Anwar, Z., Malik, T. N., and Abbas, T., "Power Flow and Transient Stability Enhancement using Thyristor Controlled Series Compensation", Mehran University Research Journal of Engineering and Technology, Vol. 37, No.4, pp. 685-700, 2018.

[11] Benabid, R., Boudour, M., and Abido, M. A., "Optimal Location and Setting of SVC and TCSC Devices Using Non-dominated Sorting Particle Swarm Optimization", Electric Power Systems Research, Vol. 79, No. 12, pp. 1668-1677, 2009.

[12] Srivastava, L., Dixit, S., and Agnihotri, G., "Optimal Location and Size of TCSC for Voltage Stability Enhancement Using PSO-TVAC", Proceedings of the IEEE Power and Energy Systems Conference: Towards Sustainable Energy, 2014.

[13] Rashed, G. I., Shaheen, H. I., and Cheng, S. J., "Optimal Location and Parameter Setting of TCSC by Both Genetic Algorithm and Particle Swarm Optimization", Proceedings of the 2nd IEEE Conference on Industrial Electronics and Applications, pp 1141-1147, 2007.

[14] Kazemi, A., Parizad, A., and Baghaee, H. R. "On the Use of Harmony Search Algorithm in Optimal
Placement of FACTS Devices to Improve Power System Security", IEEE EUROCON, IEEE, pp 570-576, 2009.

[15] Chatterjee, D., and Ghosh, A. "Application of Trajectory Sensitivity for the Evaluation of the Effect of TCSC Placement on Transient Stability", International Journal of Emerging Electric Power Systems, Vol. 8, No.1, 2007.

[16] Jayasankar, V., Kamaraj, N., and Vanaja, N. "Estimation of Voltage Stability Index for Power System Employing Artificial Neural Network Technique and TCSC Placement", Neurocomputing, Vol. 73, No.16-18, pp 30053011, 2010.

[17] Ye, Y., Kazerani, M., and Quintana, V. "Currentsource Converter Based SSSC: Modeling and Control", Proceedings of the IEEE Power Engineering Society Summer Meeting, Vol. 2, pp. 949-954, 2001.

[18] Bongiorno, M., Svensson, J., and Angquist, L, "Single-phase VSC Based SSSC for Subsynchronous Resonance Damping", IEEE Transactions on Power Delivery, Vol. 23, No.3, pp. 1544-1552, 2008.

[19] Rahim, A., and Ali, M. A. "Tuning of PID SSSC Controller Using Artificial Bee Colony Optimization Technique", Proceedings of the 11th International Multi-Conference on Systems, Signals \& Devices, pp. 1-6, 2014.

[20]El-Moursi, M. S., and Sharaf, A. M., "Novel Controllers for the 48-pulse VSC STATCOM and SSSC for Voltage Regulation and Reactive Power Compensation", IEEE Transactions on Power Systems, Vol. 20, No.4, pp 1985-1997, 2005.

[21] Castro, M. S., Ayres, H. M., Da Costa, V. F., and Da Silva, L. C. P. "Impacts of the SSSC Control Modes on Small-Signal and Transient Stability of a Power System", Electric Power Systems Research, Vol. 77, No.1, pp 1-9, 2007.

[22] Panda, S., Swain, S. C., Rautray, P. K., Malik, R. K., and Panda, G. "Design and Analysis of SSSCbased Supplementary Damping Controller", Simulation, Modelling, Practice and Theory, Vol. 18, No. 9, pp. 1199-1213, 2010.

[23] Ngamroo, I., and Kongprawechnon, W. "A Robust Controller Design of SSSC for Stabilization of Frequency Oscillations in 
Interconnected Power Systems, "Electric Power Systems Research", Vol. 67, No.3, pp. 161-176, 2003.

[24] Hajforoosh, S., Nabavi, S. M., Masoum, M. A. "Optimal Particle Swarm based Placement and Sizing of Static Synchronous Series Compensator to Maximize Social Welfare", Journal of Electrical Engineering and Technology, Vol. 7, No.4, pp. 501-512, 2012.

[25] Nabavi, S. M., Khafafi, K., Sakhavati, A., Nahi, S. "Optimal Location and Sizing of SSSC Using Genetic Algorithm in Deregulated Power Market", International Journal of Computer Applications, Vol. 22, No.4, pp. 37-41, 2011.

[26] Eghtedarpour, N., Reza, A. S. "Sensitivity-Based Method for the Effective Location of SSSC", Journal of Power Electronics, Vol. 11, No. 1, pp. 90-96, 2011.

[27] Rahimzadeh, S., Bina, M. T. "Looking for Optimal Number and Placement of FACTS Devices to Manage the Transmission Congestion", Energy Conversion and Management, Vol. 52, No. 1, pp. 437-446, 2011.

[28] Menniti, D., and Scordino, N. "A New Method for SSSC Optimal Location to Improve Power System Available Transfer Capability", Proceedings of the IEEE PES Power Systems Conference and Exposition, 2006.

[29] Abd-Elazim, S. M., Ali, E., S. "Bacteria Foraging Optimization Algorithm Based SVC Damping Controller Design for Power System Stability Enhancement", International Journal of Electrical Power and Energy Systems, Vol. 43, No. 1, pp. 933-940, 2012.

[30] Mishra, Y., Mishra, S., and Dong, Z. Y. "Rough Fuzzy Control of SVC for Power System Stability Enhancement", Journal of Electrical Engineering and Technology, Vol. 3, No. 3, pp. 337-345, 2008.

[31] Hosseini, S. H., and Mirshekar, O. "Optimal Control of SVC for Subsynchronous Resonance Stability in Typical Power System", Proceedings of the IEEE International Symposium on Industrial Electronics Proceedings, I2001.

[32] Farsangi, M. M., Song, Y. H. and Sun, Y. Z. "Supplementary Control Design of SVC and STATCOM Using Hœ Optimal Robust Control", Electric Utility Deregulation and Restructuring and Power Technologies Proceedings, 2000.
[33]Zou, Z. Y., Jiang, Q. Y. Cao, Y. J. and Wang, H. F. "Normal Form Analysis of Interactions Among Multiple SVC Controllers in Power Systems", IEE Proceedings - Generation, Transmission and Distribution, Vol. 152, No. 4 pp. 469-474, 2005.

[34]Eslami, M., Shareef, H., Mohamed, A. Khajehzadeh, M., "Coordinated Design of PSS and SVC Damping Controller Using CPSO", Proceedings of the 5th IEEE International Power Engineering and Optimization Conference, pp. 11-16, 2011.

[35] Saurav, R., Bhattacharyya, B. "Optimal Placement of TCSC and SVC for Reactive Power Planning Using Whale Optimization Algorithm", Swarm and Evolutionary Computation, Vol. 40, pp 131-143, 2018

[36] Reza, S., Mohamed, A., Shareef, H. "Optimal Placement and Sizing of Static Var Compensators in Power Systems Using Improved Harmony Search Algorithm", Przeglad Elektrotechniczny, Vol. 87, No. 7, pp. 214-218, 2011.

[37] Ayman A. A., Milanovic, J. V., "Placement and Tuning of SVCs for the Improvement of Technoeconomic Performance of the Network Based on Sequential Number Theoretic Optimization Algorithm", IEEE PES Power Systems Conference and Exp, 2006.

[38] Singh, J. G., Singh, S. N., Srivastava, S. C. "An Approach for Optimal Placement of Static VAR Compensators Based on Reactive Power Spot Price", IEEE Transactions on Power Systems, Vol. 22, No. 4, pp. 2021-2029, 2007.

[39] Siddiqui, A. S., Khan, M. T., Iqbal, F. "Determination of Optimal Location of TCSC and STATCOM for Congestion Management in Deregulated Power System", International Journal of System Assurance Engineering and Management, Vol. 8, No.1, 2017.

[40] Sirisukprasert, S., Huang, A. Q., Lai, J. S. "Modeling, Analysis and Control of Cascadedmultilevel Converter-based STATCOM", IEEE Power Engineering Society General Meeting, Vol. 4, 2003.

[41] Kavitha, K., Neela, R. "Optimal Allocation of Multi-type FACTS Devices and its Effect in Enhancing System Security Using BBO, WIPSO and PSO", Journal of Electrical Systems and 
Information Technology, Vol. 5, No.3, pp. 777793, 2018.

[42] Kothari, M. L., Patra J. C. "Design of STATCOM Controllers with Energy Storage System Using GEA", Proceedings of the 37th IEEE Annual North American Power Symposium, 2005.

[43] Mienski, R., Pawelek, R., Wasiak, I. "Application of STATCOM Controllers for Power Quality Improvement-modeling and Simulation", Proceedings of the 10th International Conference on Harmonics and Quality of Power, Vol. 2, 2002.

[44] Valle, Y. D., Hernandez, J.C., Venayagamoorthy G.K., Harley, R.G., "August. Optimal STATCOM Sizing and Placement Using Particle Swarn Optimization", IEEE/PES Transmission \& Distribution Conference and Exposition, Latin America, pp. 1-6, 2006.

[45] Samimi, A., Golkar, M. A., "A Novel Method for Optimal Placement of STATCOM in Distribution Networks Using Sensitivity Analysis by DIGSILENT Software", Proceedings of the IEEE International Conference on Power and Energy Engineering Conference (APPEEC), AsiaPacific, 2011.

[46] Aziz, T., Hossain, M. J., Saha, T. K. and Mithulananthan, N., "Stability Evaluation of Distributed Generator Integrated System with Index Based Placement of STATCOM", Proceedings of the IEEE International Conference on PES Innovative Smart Grid Technologies, pp. 1-8, 2011.

[47]Diez-Valencia, V., Annakkage, U. D., Gole, A. M., Demchenko, P. and Jacobson, D., "Interline Power Flow Controller (IPFC) Steady State Operation", Proceedings of the Canadian Conference on Electrical and Computer Engineering, Vol. 1, pp. 280-284, IEEE, 2002.

[48] Valentin, A. and Mihalic, R., "The Control Strategy for an IPFC Based on the Energy Function", IEEE Transactions on Power Systems, Vol. 23, No. 4, pp. 1662-1669, 2008.

[49] Jianhong, C., Lie, T. T., Vilathgamuwa D M., "Basic Control of Interline Power Flow Controller", Proceedings of the IEEE Power Engineering Society Winter Meeting, Vol. 1, 2002.
[50]Zhang, X. P., "Modelling of the Interline Power Flow Controller and the Generalised Unified Power Flow Controller in Newton Power Flow", IEE Proceedings on Generation, Transmission and Distribution, Vol. 150, No. 3, pp. 268-274, 2003.

[51]Ram, I. S., Amarnath, J., "Optimal Setting of IPFC for Voltage Stability Improvement Using (GA-GSA) Hybrid Algorithm", Proceedings of the Nirma University International Conference on Engineering (NUiCONE), IEEE, 2013.

[52] Karthik, B., Alagarasan, I., Chandrasekar, S., "Optimal Location of Interline Power Flow Controller for Controlling Multi Transmission Line: A New Integrated Technique", Frontiers of Electrical and Electronic Engineering, Vol. 7, No. 4, pp. 447-458, 2012.

[53] Sreejith, S., Psimon, S. and Selvan, M. P., "Optimal Location of Interline Power Flow Controller in a Power System Network Using ABC Algorithm", Archives of Electrical Engineering, Vol. 62, No. 1, pp. 91-110, 2013.

[54] Darabian, M., Jalilvand, A., "A Power Control Strategy to Improve Power System Stability in the Presence of Wind Farms Using FACTS Devices and Predictive Control", International Journal of Electrical Power and Energy Systems, Vol. 85, pp. 50-66, 2017.

[55] Vural, A. M., Tümay, M., "Mathematical Modeling and Analysis of a Unified Power Flow Controller: A Comparison of Two Approaches in Power Flow Studies and Effects of UPFC Location", International Journal of Electrical Power and Energy Systems, Vol. 29, No. 8, pp. 617-629, 2007.

[56]Huang, Z., Ni, Y., Shen, C.M., Wu, F.F., Chen, S., Zhang, B., "Application of Unified Power Flow Controller in Interconnected Power Systems-modeling, "Interface, Control Strategy, and Case Study", IEEE Transactions on Power Systems, Vol. 15, No. 2, pp. 817-824, 2000.

[57] Malhotra, U., Gokaraju, R., "An Add-on Selftuning Control System for a UPFC Application", IEEE Transactions on Industrial Electronics, Vol. 61, No. 5, pp. 2378-2388, 2014.

[58]Laifa, A., and Boudour, M., "Optimal Placement and Parameter Settings of Unified Power Flow Controller Device Using a Perturbed Particle 
Swarm Optimization", Proceedings of the Energy Conference and Exhibition, IEEE, 2010.

[59] Taher, S. A., and Amooshahi, M. K., "Optimal Placement of UPFC in Power Systems Using Immune Algorithm", Simulation Modelling Practice and Theory, Vol. 19, No. 5, pp. 13991412, 2011.

[60] Kumar, G. N., Kalavathi M. S., "Cat Swarm Optimization for Optimal Placement of Multiple UPFC's in Voltage Stability Enhancement Under Contingency", International Journal of Electrical Power and Energy Systems, Vol. 57, pp. 97-104, 2014.

[61] Aghazadeh, H., Germi, M. B., Khiav B. E., Ghadimi, N., "Robust Placement and Tuning of UPFC Via a New Multiobjective Scheme-based Fuzzy Theory", Complexity, Vol. 21, No. 1, pp. 126-137, 2015.

[62] Tang, A., Shao Y., Huang Y., Xu, Q., “A New Topology of the Distributed Power Flow Controller and its Electromagnetic Transient Characteristics", Electric Power Systems Research, Vol. 163, pp. 280-287, 2018.
[63] Shrivastava, S., Sharma, V., Bhargava, A., "Modeling and Performance Analysis of Distributed Power Flow Controller on Multi Machine System", European Journal of Advances in Engineering and Technology, Vol. 5, No. 2, pp. 99-105, 2018.

[64] Jamshidi A. S., Barakati M., Ghahderijani, M. M., "Power Quality Improvement and Mitigation Case Study Using Distributed Power Flow Controller", Proceedings of the IEEE International Symposium on Industrial Electronics (ISIE), IEEE, 2012.

[65] Bhutto G. M., Keerio M. U., Junejo A. K., "The Frequency Control in the Islanded Micro Grid by Using STATCOM Controllers", Mehran University Research Journal of Engineering and Technology, Vol. 34, No. 4, pp. 317-324, 2015.

[66]WHO Regional Office for Europe, "Urbangreenspaces: a brief for action", 2017. 